\title{
A STUDY ON MECHANICAL BEHAVIOUR OF HYBRID COMPOSITES
}

\author{
T. PRASAD ${ }^{1}$, P. CHINNA SRINIVASA RAO ${ }^{2}$, \\ B. RAJA NARENDER ${ }^{1} \&$ H. AMERESH ${ }^{2}$ \\ ${ }^{l}$ Associate Professors, Anurag Group of Institutions, Hyderabad, Telangana, India \\ ${ }^{2}$ Assistant. Professors, Anurag Group of Institutions, Hyderabad, Telangana, India
}

\begin{abstract}
Composite containing more than one type of fiber known as hybrid composites. Natural fibers and artificial fibers can be used for fabrication of Hybrid composites. Hybrid composites will give mechanical properties than fiber reinforced composites. The element of fibers in Hybrid composite, the elements of fibers can be changed in different ways leading to variation in its properties. For preparing the hybrid composites using different fibres reinforced with matrix. Hybrid composite has wider applications across industries such as aerospace, automobiles, Marine etc.

In this paper, fabrication of hybrid composites is done manually using hand lay-up method. It is then subjected to a compressive load for thorough distribution of resin in respective lamina. The fabricated composite is tested for its flexural and tensile properties. The result obtained are further analysed for the study of the material fabricated.
\end{abstract}

KEYWORDS: Hybrid Composites, Natural Fibers, Fabrication, Tensile \& Flexural

Received: Sep 22, 2018; Accepted: Oct 12, 2018; Published: Dec 06, 2018; Paper Id.: IJMPERDDEC201868

\section{INTRODUCTION}

The advantages of composite are submarines and board warships, ability to be molded into complex shapes, high strength to weight ratio, improve EMI performance, absence of corrosion palliatives which or else the resource for electronic and magnetic mark. Composite material prepared for epoxy resins and E-Glass fibers have develop into very admired as a radome material due to its stupendous intelligibility toward microwave and having good mechanical properties.

The increasing popularity of the material for underwater application are posing great difficulties to the designer to select the right combination of composition \& shape of radome due to the complex surroundings of the structure and the loading conditions for the useful operation life. Composite materials are prejudiced by several processes due to the mechanical properties. Carry out the test on regular specimens and estimate mechanical properties are the mainly imperative characteristic in the design of amalgamated material applications. The crash mechanism and micro-mechanics of composite material is extremely mixed compare to the predictable isotropic materials. Depending on the reinforcement, symphony satisfied \& its entitlement, appropriate theory \& failure mechanism can be considered for deceitful the random finished of E- Glass epoxy composite.

The statement composite resources combination of two or supplementary distinct parts. Thus a material has two or more chemically dissimilar constituent or phases, on macro scale, having a distinct interface separating them, may be measured a composite material. It is different from the constituent, only when the element phases 
have significantly dissimilar physical properties and thus the composite properties are noticeably properties that we have come to distinguish these materials as composites, composites, frequently referred to as current structural composites are a combine of two or more components, one of which is made up of rigid, long fibers, and the other, a binder or matrix which holds the fibers in place. The fibers are regid and strong relation to the matrix and are generally orthotropic (having different properties in two different directions). The fiber, for complex structural composites, is stretched, with aspect ratio (length to diameter ratios) of more than 100.

\section{METHODOLOGY}

\section{Manufacturing Process of the Composite Laminate}

\section{Material Required}

The different materials and components required for this mechanized process of glass epoxy composite are as below.

Table 1

\begin{tabular}{|c|l|c|}
\hline S.No & \multicolumn{1}{|c|}{ Materials } & Quantity \\
\hline 1 & Fiber & $1863.2 \mathrm{~g}$ \\
\hline 2 & Epoxy Resin LY-556 & $804.64 \mathrm{~g}$ \\
\hline 3 & Hardner HY-556 & $1000 \mathrm{~g}$ \\
\hline 4 & Fly ash & $21.12 \mathrm{~g}$ \\
\hline 5 & Teflon Sheet $\left(1^{*} 1\right) \mathrm{m}$ & 1 \\
\hline 6 & Measuring Jar & 2 \\
\hline 7 & Stirring Rod & 1 \\
\hline 8 & Gloves & 8 \\
\hline 9 & Portable Weighting Machine & 1 \\
\hline 10 & Weights & \\
\hline 11 & Scissors & 1 \\
\hline
\end{tabular}

\section{Determination of Essential Epoxy Resin and Glass Fiber}

Generally for measure the required amount of materials for manufacturing composite laminate, we need an electronic weighing machine which measure exactly in grams. In this paper we are using dissimilar ratios of glass fiber to epoxy resin.

Table 2: Ratios of Glass Fiber to Epoxy resin and Fly ash

\begin{tabular}{|c|c|c|c|}
\hline S.No. & Ratio of Glass Fiber & Ratio of Epoxy Resin & Ratio of Fly Ash \\
\hline 1 & $60 \%$ & $40 \%$ & $0 \%$ \\
\hline 2 & $60 \%$ & $39 \%$ & $1 \%$ \\
\hline 3 & $60 \%$ & $37 \%$ & $3 \%$ \\
\hline 4 & $60 \%$ & $35 \%$ & $5 \%$ \\
\hline
\end{tabular}

For influential the exact weight of the material, we necessitate to find out the density of the glass fiber. Density formulae can be given as

$$
\mathrm{d}=\mathrm{m} / \mathrm{v}
$$

Where $\mathrm{d}=$ density

$$
\begin{aligned}
& \mathrm{m}=\text { mass } \\
& \mathrm{v}=\text { volume }
\end{aligned}
$$


Density of fiber $=0.97 \mathrm{~g} / \mathrm{cm}^{3}$, density of matrix $=1.125 \mathrm{~g} / \mathrm{cm}^{3}$, density of Fly ash $=1.2 \mathrm{~g} / \mathrm{cm}^{3}$

Volume of the composite (mould) $=300 * 300 * 5 \mathrm{~mm}$

$$
=450 \mathrm{~cm}^{3}
$$

Volume of the Composite $=$ Volume of fiber + Volume of Matrix

Volume of Fiber $=60 \%$ of Vol. of Composite

$$
\begin{aligned}
& =60 *(450 / 100) \\
& =270 \mathrm{~cm}^{3}
\end{aligned}
$$

Hence mass of fiber $=$ Vol. of Fiber $*$ Density of fiber

$$
=270 * 0.97=261.9 \mathrm{~g}
$$

\section{Preparation of Mould}

For making the test specimen, composite laminates are prepared on a wooden mould of dimensions $30 * 30 \mathrm{~cm}^{2}$ as shown in fig.

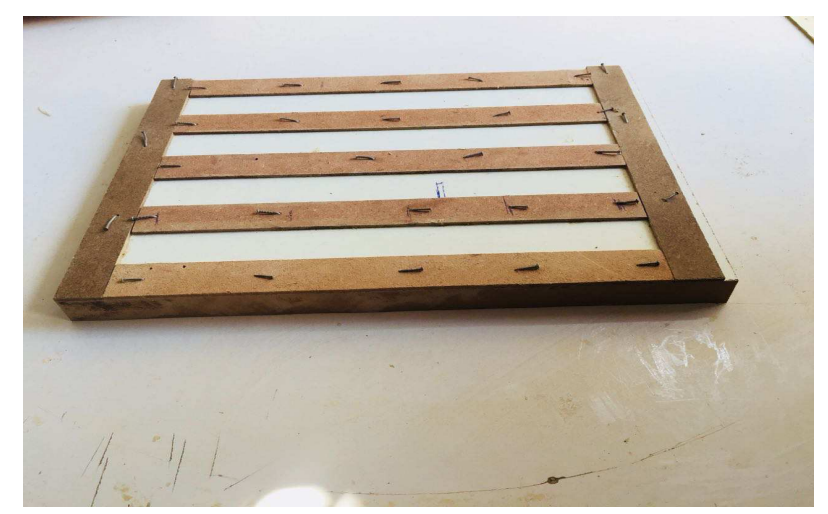

Figure 1: Wooden Mould to Arrange Composite Material

\section{Cutting Glass Fibre}

Glass fiber have to be cut into more than a few layers, each of dimensions $250 * 250 \mathrm{~mm}$ so that it will exactly fit into the mould. Normal blade can be used to cut the glass fiber, and the weight can be measured by electronic weighing machine.

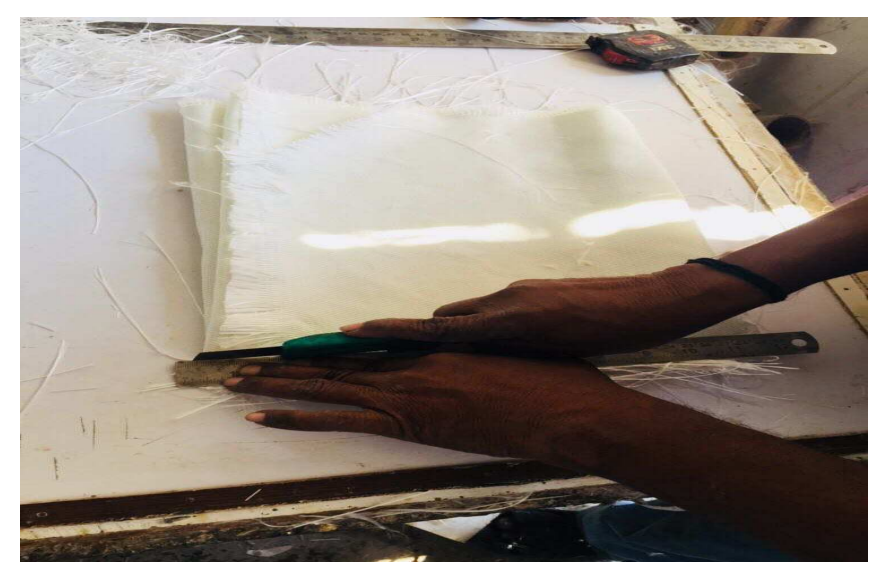


Figure 2: Cutting of Glass Fiber

\section{RESULTS}

\section{Testing of Specimen}

Specimen used for testing to be cut into two different shapes for different tests. For tensile test it should be in dimensions of $250 * 25 * 2 \mathrm{~mm}$ for flexural test it should be in dimensions of $250 * 25 * 2 \mathrm{~mm}$

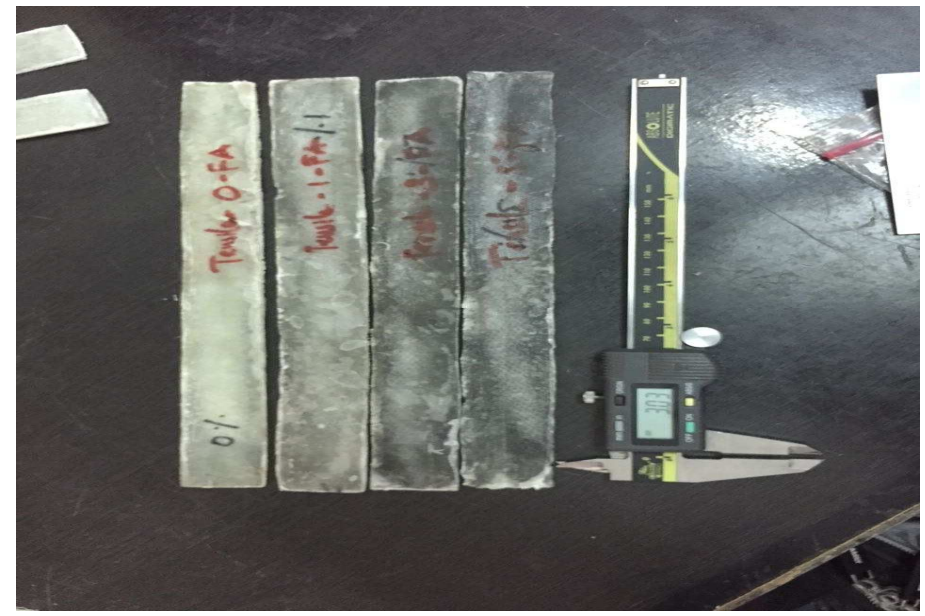

Figure 3: Specimen for Tensile Test

\section{Tensile Test Results}

Table 3

\begin{tabular}{|c|c|c|c|}
\hline Fiber \% & Resin \% & Fly ash \% & Ultimate Strength I N/mm \\
\hline 60 & 40 & 0 & 81.869 \\
\hline 60 & 39 & 1 & 96.825 \\
\hline 60 & 37 & 3 & 68.954 \\
\hline 60 & 35 & 5 & 67.321 \\
\hline
\end{tabular}

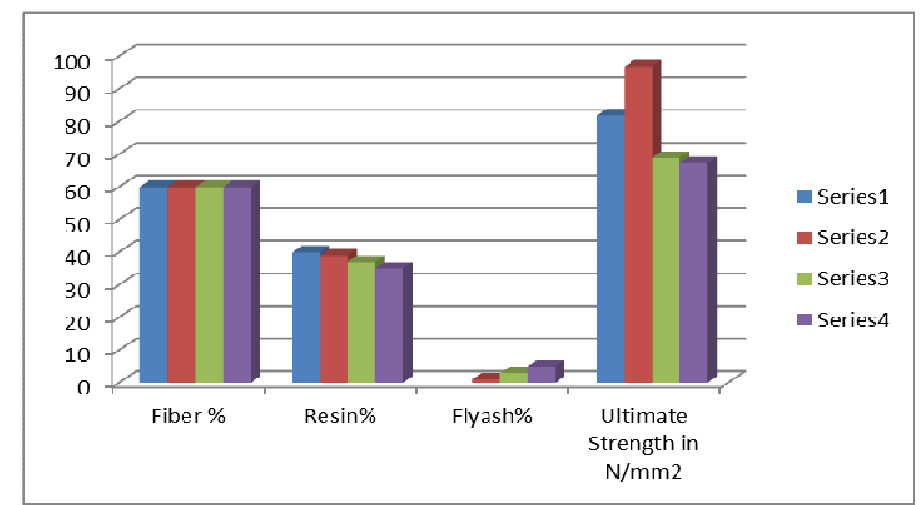

Figure 4 Tensile Test Analysis 


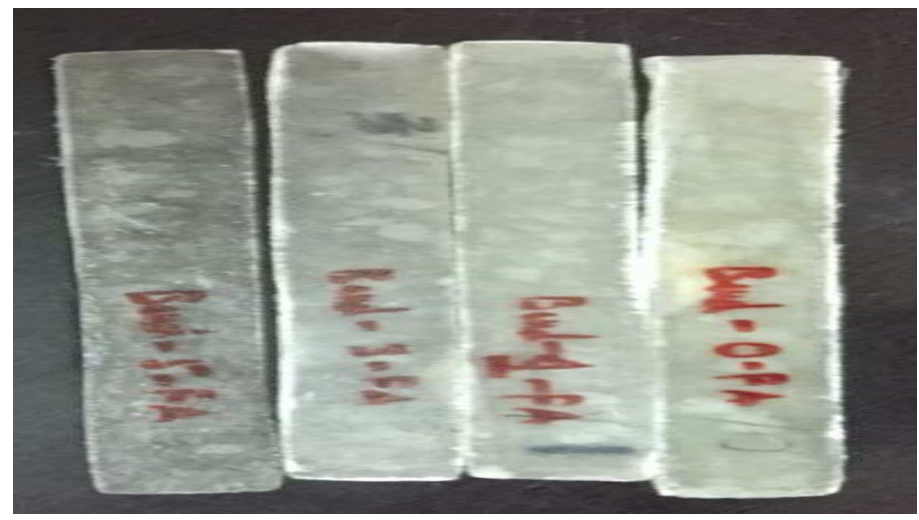

Figure 5: Specimens for Flexural Test

\section{Flexural Test Results}

Table 4

\begin{tabular}{|c|c|c|c|}
\hline Fiber \% & Resin \% & Fly ash\% & $\begin{array}{c}\text { Flexural Strength in } \\
\mathbf{N} / \mathbf{m m}^{\mathbf{2}}\end{array}$ \\
\hline 60 & 40 & 0 & 22.13 \\
\hline 60 & 39 & 1 & 25.32 \\
\hline 60 & 37 & 3 & 20.24 \\
\hline 60 & 35 & 5 & 25.47 \\
\hline
\end{tabular}

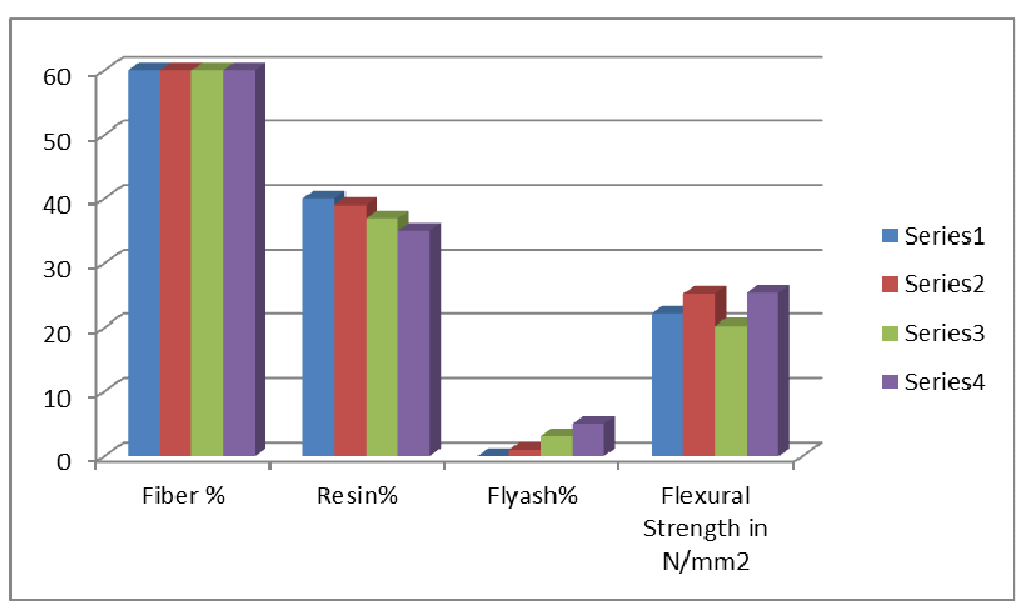

Figure 6: Flexural Test Analysis

\section{CONCLUSIONS}

- The composite material shows the percentage increase in fly ash up to $1 \%$ with higher tensile strength. The matter with less percentage of fly ash and high percentage of epoxy has high tensile strength. And the material with a high percentage of fly ash and low percentage of epoxy has less tensile strength.

- The composite material possesses high strength in the compositions of $0 \%$ and $1 \%$ of fly ash than that of $3 \%$ and $5 \%$ of fly ash.

- The composite material shows high flexural strength by means of percentage increase in fly ash up to $1 \%$. The material with low percentage of fly ash and high percentage of epoxy has high flexural strength. And the material with a high percentage of fly ash and low percentage of epoxy has low flexural strength. 
- The composite material possesses high strength in the standard compositions of $0 \%$ and $1 \%$ fly ash than that of $3 \%$ and $5 \%$ fly ash.

\section{REFERENCES}

1. “Analysis and performance of fiber composites “. Agarwal BD and Boutman LJ, John Wiley and sons.

2. “Mechanics of composite materials”. Jones RM, Mcgraw Hill.

3. Titterton G, "Aircraft materials and process", 5 edition.

4. Greenhalgh RJS, Baynham E, Evans Dm Canfer S, Roberton S, Morrow D, Temple S. “ Strength of epoxy-resin-based insulation systems in transvers tension and shear uingin two novwl test pieces". International Journal of Adhesion \& Adhesives 2003: 23(6): 485-494.

5. Peter Ifju P, Myers D, Schulz W. Residual stress and thermal expansion of graphite epoxy laminates subjected to cryogenic temperature. Composites Science and Technology 2006; 66(14): 2449-2455.

6. Saniee FF, Majzoobi GH, Bahrani M. "An experimental study on the behavior of glass-epoxy composite at low strain rates". Journal of Material Processing Technology 2005; 162-163 (1): 39-45.

7. Ray BC. "Thermal shock and thermal fatigue on delamination of glass fiber reinforced polymetric composites. Journal of Reinforced Plastics and Composites 2005; 24(1): 39-45.

8. Cindy Foreman, "Advanced composites".

9. Lubin G, Hand book of advanced plastics and fiber glass".

10. “Advanced composite materials”, Lalit Gupta. 